\title{
Pattern of species occurrence in detritus-based communities with variable connectivity
}

\author{
Bruno Bellisario, Fulvio Cerfolli and Giuseppe Nascetti
}

Bellisario, B., Cerfolli, F. and Nascetti, G. 2011. Pattern of species occurrence in detritus-based communities with variable connectivity. - Web Ecol. 11: 1-9.

\begin{abstract}
Patterns and mechanisms of species occurrence in space and time are outstanding questions in community and conservation ecology. Much of the current debate focuses on randomness or non-randomness in the structuring process of ecological communities, and the extent to which local/deterministic or regional/stochastic processes may drive their composition. However, a categorical subdivision could be misleading, as community composition may be driven by a continuum between neutral- and niche-based processes. For instance, in spatially structured systems local processes may surpass regional processes over time or across space to derive non-random metacommunity structure, suggesting the filtering role of the environment in mediating the pattern of species occurrence. In this work we study the temporal composition of detritus-based communities, which are an essential component in many aquatic and terrestrial ecosystems. We used data about macroinvertebrate colonization of leaf detritus in different sites of a patchy-connected system, to measure the co-occurrence of species on the detrital resource and evaluate the role of the spatial configuration and the environmental variability in determining the community's composition. Our results show the importance of considering the joint role of regional and local processes in mediating stochastic and deterministic mechanisms in species assemblage, with important outcomes from a conservation point of view.
\end{abstract}

B. Bellisario (bruno.bellisario@unitus.it),F. Cerfolli and G. Nascetti, Dept of Ecology and Sustainable Economic Development, Univ. of Viterbo, L. go dell'Univ., Blocco C snc, IT01100 Viterbo, Italy.

Studies on the composition of ecological communities have revealed that species aggregation in space and time may follow random or non-random patterns (Diamond 1975, Patterson and Atmar 1986). When the occurrence of species within the communities follows randomness, the presence of regional stochastic processes can drive their composition (Hubbel 2001), whilst non-random patterns are likely to occur when local deterministic mechanisms (e.g. spatial and temporal niche partitioning) drive the shape of a community (Chase and Leibold 2003). However, several authors (Bell 2001, Ulrich 2004) argued that pure stochastic processes (e.g. dispersal or local extinction) generate non-random patterns in species co-occurrence, suggesting that not only species interactions (Tilman 1982, Weiher and Keddy 1999) but also stochastic drift processes may drive community structure (Schoener and Adler 1991, Bell 2001). For instance, local processes may surpass regional processes over time or across space to derive non-random metacommunity structure (the so-called 'quorum' effect, Jenkins 2006), suggesting the role of the environmental variability in mediating stochastic vs deterministic processes (Elwood et al. 2009). This also suggests 
the need of a full integration of dispersal- and niche-based concepts in metacommunity dynamics for unraveling the community assembly (Jenkins et al. 2006).

The extent to which species within the communities follow or not well-defined patterns of association represents a fundamental issue in community and conservation ecology. Why and how species colonize habitats and resources represent intriguing questions about the ecological and evolutive mechanisms behind species aggregation in space and time (Strauss and Irwin 2004). The pattern of colonization then reflects some specific mechanisms in the co-occurrence of species, which in turn may express the extent to which interspecific competition is involved in a community's composition (Diamond 1975). Species occupying similar niches are expected to never occur due to competitive exclusion and, therefore, in a competitively structured community there should be more 'checkerboard pairs' than expected by chance (Gotelli 2000).

The potential mechanisms behind species co-occurrence can be inferred only after establishment of whether this pattern deviates from that expected under random processes (Connor and Simberloff 1979, Gotelli 2000). Different mechanisms are involved in the pattern of species co-occurrence in community composition, where facilitative interactions or shared preferences allow species to co-occur more often than expected by chance (Krasnov et al. 2006). On the other hand, interspecific competition (Diamond 1975) or differential preferences (Pielou and Pielou 1968) allow species to co-occur less frequently than expected by chance, and communities are expected to be segregatively structured (Diamond 1975, Gotelli and Rohde 2002). Randomness or non-randomness in community composition also have the potential to influence key ecosystem functions (Jonsson et al. 2008), highlighting the role of extinction/colonization dynamics in explaining the functional consequences of community level processes (Fukami et al. 2010).

With up to $90 \%$ of global terrestrial plant production entering the dead organic matter pool (Cebrian 1999), decomposition and the sequestration of organic carbon in soils and sediments stand out as central components of ecosystem functioning (Gessner et al. 2010). Invertebrate communities of leaf litter consumers play an essential role by recycling nutrients, sustaining higher species diversity, a larger biomass of predators and longer food webs than would be supported by primary production alone (Hairston and Hairston 1997), and stabilizing the dynamics of consumer populations and food webs that would otherwise be unstable (reviewed by Moore et al. 2004). A complex suite of interactions typically occurs between the organisms involved in the colonization of detrital substrates. Competition for resources, predation and facilitative interactions may determine the composition of communities, regulating the dynamics between trophic levels and the rate at which detritus is decomposed (Moore et al. 2004). Detritus also has the ability to serve not only as a trophic resource, but also as habitat for many invertebrate species and as refuge from predation, especially by fish, such that density-mediated trophic cascades may not occur (Reice 1991, Rosenfeld 2000).

Further, differences in habitat conditions, such as differences in geometric characteristics (e.g. connectivity) or environmental conditions, are thought to influence the way with which species tend to organize within a community, and this may create contrasting selection pressures that shape the evolutionary trajectories of the organisms involved in the colonization of detrital resources in different ways (Gessner et al. 2010). Recently, it has been suggested (Chase 2007) that the harshness of the environmental conditions operating in local habitats may act as a filter between stochastic and deterministic processes in community composition, and this variability is often related to the spatial configuration of local patches and/or habitats (Fisher and Lindenmayer 2007).

Here we explore the mechanisms involved in the temporal colonization of Phragmites australis leaf detritus in a patchy aquatic environment. Specifically, we want to address if the pattern of co-occurrence of macroinvertebrates on leaf detritus in time deviates from randomness, and if so, if it determines the mechanisms and the causes behind community composition. We predict that in a spatially connected system, the habitat connectivity may exert a significative influence in regulating the variability of the local environmental conditions and the pattern of species co-occurrence in detritus-based communities, with important outcomes also from a conservation point of view.

\section{Material and methods}

\section{Study area and field experiment}

The study area is the transitional aquatic environment of Tarquinia saltern $\left(42^{\circ} 12^{\prime} \mathrm{N}, 11^{\circ} 43^{\prime} \mathrm{E}\right)$, an artificial ecosystem composed by a series of pools whose connection is ensured by a drainage system surrounding the pools, and where the exchange of water is given by a single connection with the sea located north of the area (Fig. 1).

We chose five sampling sites representative of the entire area, and placed in each site 48 unprotected leaf packs filled with a known weight $(2.000 \pm 0.004 \mathrm{~g}$ after drying at $60^{\circ} \mathrm{C}$ for $72 \mathrm{~h}$ ) of $P$. australis leaf detritus. The field experiment lasted for 12 months and, on a monthly sampling with 4 replicates, we measured the number of taxa (S) colonizing the leaf packs, the number of individuals for each taxon (n) and the main chemical-physical parameters $(\mathrm{pH}$, dissolved oxygen concentration and salinity). The macroinvertebrates were identified to genus level and, where possible, to species level (Appendix 1, Table A1). Although aquatic macroinvertebrates may be divided in different trophic guilds (e.g. grazers, scrapers, herbivores, 

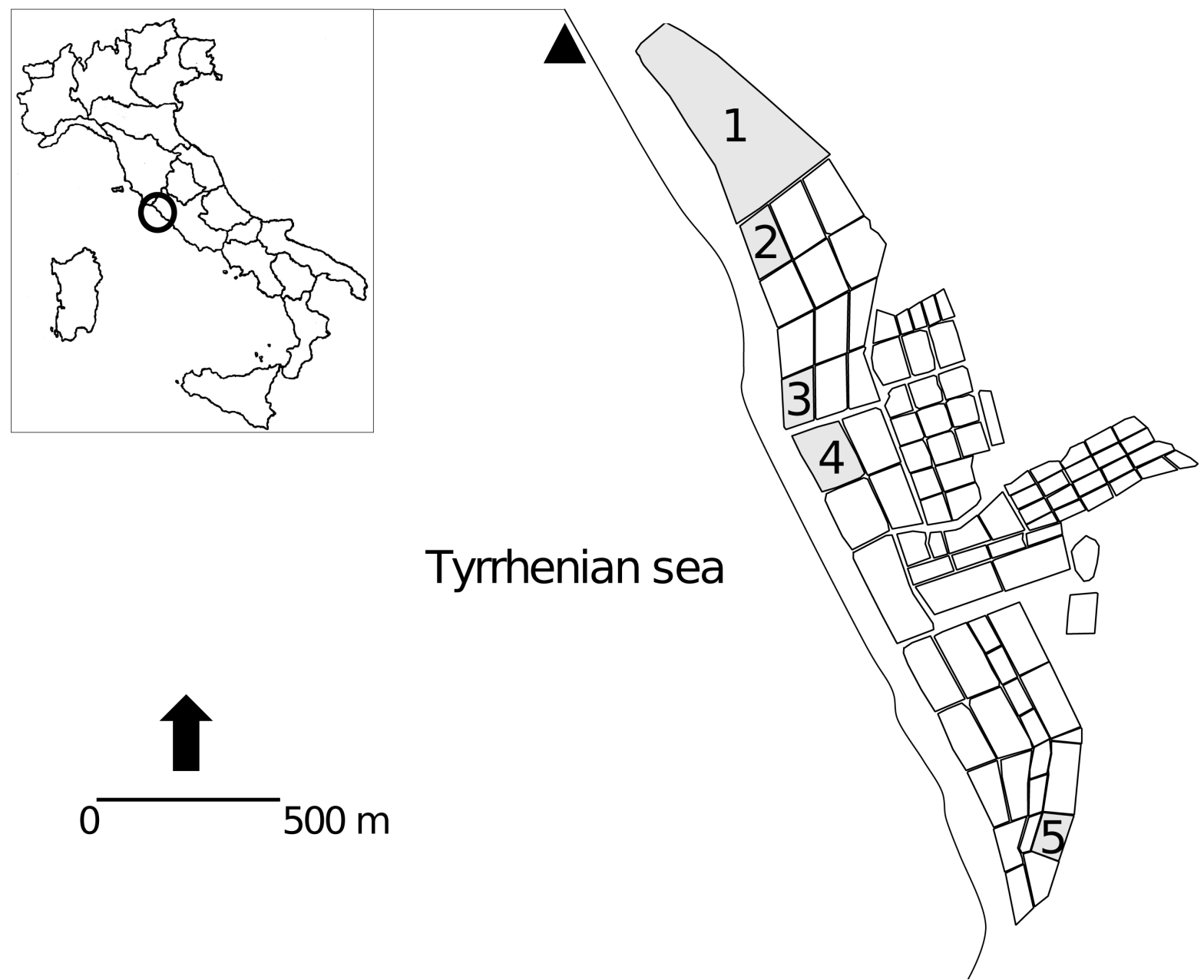

Figure 1. Geographic localization and spatial configuration of the study area, with the numbered gray areas representing the sampling stations. The black filled triangle is the point of water refill, which ensures the recycling of the water within the system.

predators), in this paper we did not use this information for two main reasons. First, the level of taxonomic resolution did not allow to achieve the same degree of recognition for all sampled taxa; second, temporal diet shift and omnivores are common in many invertebrates species, so that a categorical subdivision may overestimate or underestimate the role that a particular taxon has in the community, increasing the degree of uncertainty.

\section{Data organization and co-occurrence pattern}

For each sampling site, we organized the data as a presence/absence matrix with taxa on rows and time on columns. The entries in the matrix represent the absence (0) or presence (1) of a particular macroinvertebrate in a given sampling time.

We then measured the checkerboard distribution of taxa (Diamond 1975), which expresses the degree to which interspecific competition between taxa occupying similar niches results in a non-random pattern of species distributions. In particular, some taxa pairs may never be found in the same community due to competitive exclusion. Therefore, in a competitively structured community, there should be more such checkerboard pairs than expected by chance (Gotelli 2000). The pattern of co-occurrence among macroinvertebrates on the detrital resource in time was investigated using the C-score index (Stone and Roberts 1990), which quantifies the number of 'checkerboard units' that can be found for each species pair. The C-score is defined as the average number of checkerboard units (a $2 \times 2$ sub-matrix taking the form $01-10,10-01$ ) for each unique pair of taxa (Stone and Roberts 1990).

A null model of taxa co-occurrence was used to statistically determine if observed co-occurrence patterns could also be obtained by chance. We used the software EcoSim v. 7.0 (Gotelli and Entsminger 2010), to compare the observed C-scores with a distribution frequency of simulated 
C-scores after 1000 randomizations of the original data matrices. A sequential swap permutation algorithm was used in all analyses, using the algorithm SIM9 (Gotelli 2000, Gotelli and Entsminger 2010) which maintains fixed sums for row and column totals, so each matrix generated has the same number of taxa and number of samples as the original matrix (Connor and Simberloff 1979). This algorithm has a low chance of falsely rejecting the null hypothesis (type I error), but has good power for detecting non-random patterns (Gotelli 2000). To compare the degree of assemblage organization among the sampling sites, we used the standardized C-score (SES, standardized size effect). The SES measures the number of standard deviations in which the observed C-score is above or below the mean simulated index (Gotelli and McCabe 2002, Sanders et al. 2003). The standardized C-score measures the degree of non-randomness of assemblage organization, in this case, if macroinvertebrate assemblages tend toward segregation or aggregation. A C-score larger than expected by chance $\left(\mathrm{C}_{\text {observed }}>\mathrm{C}_{\text {expected }}\right)$ indicates negative co-occurrence (i.e. species are segregated), whilst a $\mathrm{C}$-score smaller than expected by chance $\left(\mathrm{C}_{\text {observed }}<\mathrm{C}_{\text {expected }}\right)$ indicates positive co-occurrence (i.e. species are aggregated) (Gotelli 2000, Gotelli and McCabe 2002, Gotelli and Rohde 2002).

\section{Environmental variability}

The isolation and hydrological connectivity within the study area give rise to a wide salinity gradient (Bellisario et al. 2010). Moreover, other studies (Angeletti et al. 2010) have shown the existence of a geographic pattern in the variability of other environmental parameters, which contribute to a marked species turnover and a strong temporal dynamic in community composition.

We quantified the degree of environmental variability by considering the coefficient of variation of $\mathrm{pH}$, salinity and dissolved oxygen concentration, which showed greater fluctuations within and between the pools during the time of the experiment (Appendix 2, Table A2). The coefficients of variation were subjected to principal component analysis (PCA), to reduce variation in the original dataset to a single component describing the environmental variability within the sampling sites. The resulting scores of the first axis of the PCA were normalized in a range between 0 (low variability) and 1 (high variability), and then used in subsequent analyses.

\section{Connectivity}

Let us consider a system composed by $\mathrm{x}$ patches (i.e. the pools) connected to a single point of water refill $j$, located at a distance $\mathrm{d}$ from each patch in the system. The degree of connectivity can then be measured as:

$$
P_{i}=\sum_{i j} e^{-\alpha d_{i j}} n_{i}
$$

with $\mathrm{d}_{\mathrm{ij}}$ the (euclidean) distance between the pool $\mathrm{i}$ and the point of water refill $j$ (expressed in $\mathrm{km}$ ), $n_{i}$ the estimated population size (e.g. number of individuals) of a generic taxon in leaf pack in $\mathrm{i}$, and $\alpha$ the scale effect of distance on connectivity.

Equation 1 is based on the original formulation given by Hanski (1994) and Moilanen and Hanski (2001), where high values indicate high connectivity (i.e. low isolation) than smaller values. The equation then considers the degree of connectivity (or its inverse, isolation) as a function of the distance to a given patch and the population size of a given recipient patch, jointly accounted for the scale parameter. However, when the information about dispersal is not available, $\alpha$ can be set as 1 , without significantly affecting the estimated value of $\mathrm{P}_{\mathrm{i}}$ and the rank order of connectivity (Hanski 1999).

Here we extended the measure of connectivity given by Eq. 1 in a metacommunity context, considering the population's size of all taxa composing a community:

$$
\mathrm{P}_{\mathrm{i}}=\sum_{\mathrm{i} j} \mathrm{e}^{-\mathrm{d}_{\mathrm{i}}} \sum_{s=1, s \mathrm{i}}^{\mathrm{S}} \ln \left(\mathrm{n}_{\mathrm{si}}\right)
$$

where $\mathrm{n}_{\mathrm{si}}$ is the (average) population size of taxa $\mathrm{s}$ in the leaf packs in pool i, log-transformed to improve normality, and $S$ the total number of sampled taxa that have colonized the leaf packs. It is easy to show that, for $S=1$ (i.e. a single taxon system), Eq. 2 reduces to Eq. 1.

\section{Statistical analyses}

To understand if richness and the total number of incidences influence the randomization process and the results produced by the null model, we conducted a linear regression of the number of sampled macroinvertebrate $(S)$ and the incidences (I) on the standard deviation of the randomized distribution and the standardized effect size (Gotelli and Rohde 2002, Tello et al. 2008). To test for a correspondence between the variables, we used generalized linear models (GLMs) with the $\mathrm{C}$-score index as a response parameter, and the connectivity and PCA scores as fixed parameters, assuming, respectively, the dependence (i.e. connectivity influences the environmental variability) and the independence (i.e. connectivity does not influence the environmental variability) of fixed parameters.

\section{Results}

The pattern of macroinvertebrate co-occurrence on leaf detritus along the sampling period showed significant albeit lower C-scores than those obtained by the randomization algorithm for all analyzed communities (Table 1). 
Table 1. Results from the null-model analysis of temporal occurrence of macroinvertebrate on leaf detritus. For each site we report the number of sampled taxa $(S)$, the total number of incidences $(\mathrm{I})$, the observed C-score $\left(\mathrm{C}_{\text {obs }}\right)$, the expected $\mathrm{C}$-score $\left(\mathrm{C}_{\text {exp }}\right.$, the mean of the $\mathrm{C}$-scores of the null matrices), the standard deviation of the null distribution $\left(\mathrm{SD}_{\text {sim }}\right)$, the level of significance $(\mathrm{p})$ and the standardized effect size (SES).

\begin{tabular}{lccccccc}
\hline Pool & $\mathrm{S}$ & $\mathrm{I}$ & $\mathrm{C}_{\text {obs }}$ & $\mathrm{C}_{\text {exp }}$ & $\mathrm{SD}_{\text {sim }}$ & $\mathrm{p}$ & $\begin{array}{c}\mathrm{SES} \\
\left(\mathrm{C}_{\text {obs }}-\mathrm{C}_{\text {exp }}\right) / \mathrm{SD}_{\text {sim }}\end{array}$ \\
\hline 1 & 9 & 35 & 2.636 & 3.816 & 0.542 & 0.032 & -2.176 \\
2 & 10 & 24 & 2.472 & 3.202 & 0.356 & 0.041 & -2.053 \\
3 & 4 & 18 & 0.109 & 0.711 & 0.216 & $<0.001$ & -2.788 \\
4 & 4 & 23 & 0.164 & 0.791 & 0.230 & $<0.001$ & -2.722 \\
5 & 3 & 13 & 0.018 & 0.363 & 0.139 & $<0.001$ & -2.475 \\
\hline
\end{tabular}

The number of taxa did not influence the variability in the null distribution $(r=0.826, p=0.084)$, and did not have a significant correlation with the SES $(\mathrm{r}=0.881, \mathrm{p}=0.059)$. The total number of incidences increased the possibility of more configurations for the randomized matrices, and consequently increased the variability in the null distribution $(r=0.928, p=0.022)$, but did not influence the power of null analysis $(\mathrm{r}=0.529, \mathrm{p}=0.358)$. The standardized C-score (SES) indicated the trend in assemblage organization along the sampling period (Fig. 2), showing the tendency of macroinvertebrate to aggregate during the colonization process of leaf detritus.

The best model describing the co-occurrence of taxa in time was given considering the dependence between the connectivity of the pools with the point of water refill and the environmental variability within the pools, whilst

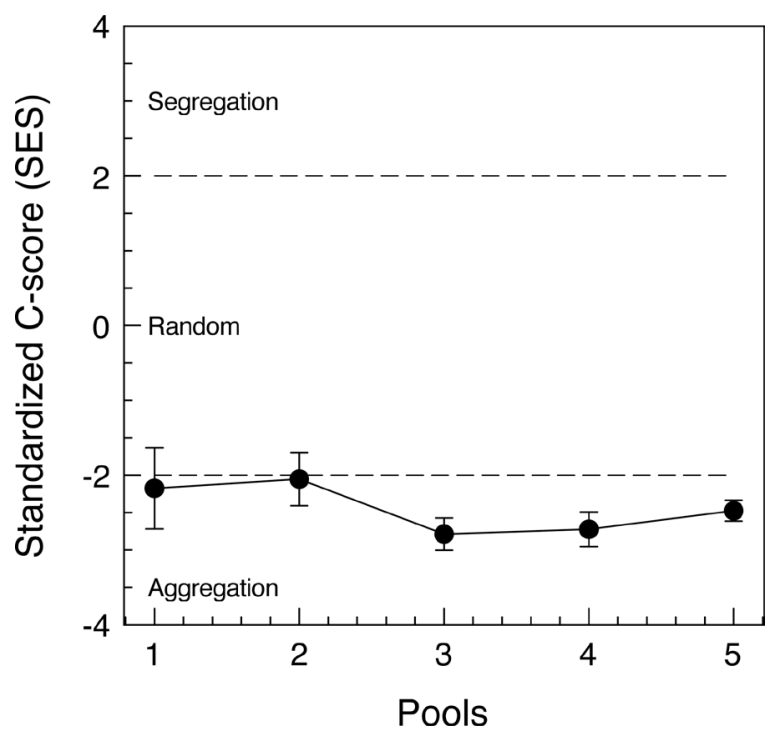

Figure 2. Level of organization (random, aggregation and segregation) of the taxa assemblages on leaf detritus in time given by the standardized C-score $\left(\mathrm{SES} \pm \mathrm{SD}_{\text {sim }}\right)$. nor the connectivity, neither the PCA scores alone gave significant results (Table 2). Further, the environmental conditions within the pools was slightly affected by the fluctuations in the level of $\mathrm{pH}$ and dissolved oxygen concentration, with the PCA ordination that explained $83.41 \%$ of total variance, mainly attributable to the variation of salinity within the pools $(r=0.96)$, which showed a significant correlation with the connectivity (Spearman's $\rho$ correlation: $\rho=-0.995, \mathrm{p}<0.01$ ).

\section{Discussion}

Understanding the patterns and mechanisms of species aggregation in space and time remain a focus of ongoing debate in community ecology. In this work we test the hypothesis that macroinvertebrate assemblage on leaf detritus follows a non-random, aggregative pattern of temporal occurrence, exploring the possible mechanisms that shape the structuring of communities. Our results have revealed non-randomness in the pattern of species co-occurrence, showing the tendency of macroinvertebrates to aggregate on the detrital resource during the colonization process. The observed C-scores for all analyzed communities are lower than expected by chance, and this reveals how the competition between the organisms involved in the colonization of detrital resource could not be the main mechanisms in community organization. This result highlights the role of other types of mechanisms, such as facilitation or shared preferences, which may drive the structuring process of communities.

Facilitative interactions, a type of ecosystem engineering, have been shown in many ecosystems, and especially in detritus-based communities (Lawton 1994, Paradise and Dunson 1997) where detritus feeders may alter the structural composition of the detrital resource, facilitating the colonization of more species. Although not explicitly analyzed in our work, we can suppose that other sources of facilitation can be determined by the degree of microbial conditioning, which can affect the colonization of inver- 
Table 2. Generalized linear models of the relationship between the temporal co-occurrence of macroinvertebrates on leaf detritus (C-score), connectivity $\left(\mathrm{P}_{\mathrm{i}}\right)$ and the environmental variability given by the first axis of the PCA ordination of sampling parameters (Appendix 2, Fig. A1).

\begin{tabular}{|c|c|c|c|c|c|c|}
\hline Response variable & Fixed effects & Fixed terms & $\mathrm{DF}$ & logLikelihood & $\mathrm{F}$ & $\mathrm{p}$ \\
\hline \multirow[t]{3}{*}{ C-score } & no dependence between fixed terms & & & 1.554 & & \\
\hline & & $\mathrm{P}_{\mathrm{i}}$ & 3 & & 7.647 & 0.151 \\
\hline & & PCA & 2 & & 0.766 & 0.474 \\
\hline
\end{tabular}

dependence between fixed terms

$-2.867$

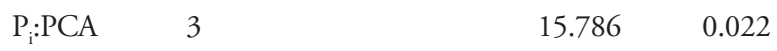

tebrate species by altering the chemical-physical composition of the detrital resource (Gessner et al. 2010). Indeed, the quality of detritus is often tied to the degree of microbial and microfungi colonization, such that they may be considered as grouped entities, so that higher consumers in the detrital branch may not distinguish between the consumption of detritus and the microorganisms that feed on it (Moore et al. 2004, Hladyz et al. 2009).

Theory predicts that a trade-off between facilitative and competitive interactions is likely to occur under different environmental conditions (Bertness and Callaway 1994). In particular, competition should occur more often under relatively stable environmental conditions, whilst facilitative interactions should occur under stressed environmental conditions (the so-called 'stress gradient hypothesis', Bertness and Callaway 1994). Null-model outcomes have shown differences in the pattern of aggregation on leaf detritus. Communities subjected to high variable conditions show a more aggregative pattern than communities subjected to more stable conditions, which are closer to a random assemblage in community composition. This result is partly due to the influence of the number of total incidences on the variability of the null model, increasing the number of possible configurations of the randomized matrices. However, the non-significant association with the SES seems to confirm that the pattern of taxa assemblage in these communities is most likely to be related to the different resource requirements associated with ecological succession and niche partitioning (Tokeshi 1999).

However, it should be noted that the communities we studied in this work represent a set of local communities that are linked by dispersal of multiple, potentially interacting taxa (i.e. metacommunity, sensu Leibold et al. 2004), where habitat connectivity can alter a variety of ecological mechanisms, such as extinction (Gonzalez and Chaneton 2002), species interactions (Tewksbury et al. 2002), patterns of movement (Haddad and Tewksbury 2005) and spatial biodiversity (Staddon et al. 2010). Here we show that the spatial configuration of the study area, that is, the degree of connectivity/isolation of the pools from the point of water refill, exerts a strong influence on the pattern of occurrence. We suppose that connectivity plays a dual role in influencing the structuring of communities, by decreasing the passive dispersal, and altering the hydrological conditions within the pools. Knowledge of dispersal strategies and rates in plants and animals is essential to understand species distribution and coexistence patterns. Aquatic invertebrates have developed a diverse array of dispersal strategies, mostly related to passive dispersal (Bilton et al. 2001), where connectivity can act as important dispersal pathways (Michels et al. 2001, Van de Meutter et al. 2006). The aggregative patterns observed in our communities are likely to be determined by the joint effect of regional (i.e. spatial variables) and local (i.e. environmental variability) processes, which might contribute to the temporal colonization of macroinvertebrates on the detrital resource. Community structure could therefore be guided by the correlation between the spatial and environmental characteristics of the sites (Spencer et al. 2002), with connectivity that affects the degree of environmental variability, mostly attributable to the salinity. This suggest that differences in community structure can arise through either neutral- and niche-based processes, also suggesting the filtering role of the environment in mediating stochastic (e.g. dispersal or local extinction) and deterministic (e.g. niche partitioning) events, largely explained by facilitative interactions.

Understanding why and how species aggregate within the communities represents a fundamental issue for conservation, suggesting that habitat management may have important outcomes for the whole ecosystem integrity and functioning, especially when the conservation passes through the active management. The increased connectivity could lead to increased homogeneity of different (local) habitats, and this could influence the pattern of occurrence (e.g. some taxa could disappear due the increased competition). On the other hand, a decreased connectivity could favor the fragmentation of local habitats, altering the spatial characteristics and decreasing biodiversity (Chisholm et al. 2011). However, some fundamental issues need to be explored for a clear understanding of the consequences of natural and human-induced alterations on biodiversity. 
For instance, detritus is a heterogeneous resource for many invertebrate and vertebrate species and intimately linked with grazer food webs, suggesting the need of a deeper knowledge of the feeding behavior of the organisms involved in its colonization. Promising techniques, such as diet molecular analyses (Valentini et al. 2009) could shed light on the trophic composition of detritus-based communities, disentangling the effect of different mechanisms involved in community compositions.

\section{References}

Angeletti, D. et al. 2010. Genetic diversity of the killifish Aphanius fasciatus paralleling the environmental changes of Tarquinia salterns habitat. - Genetica 138: 1011-1021.

Bell, G. 2001. Neutral macroecology. - Science 293: 2413-2418.

Bellisario, B. et al. 2010. Spatial network structure and robustness of detritus-based communities in a patchy environment. - Ecol. Res. 25: 813-821.

Bertness, M and Callaway, R. M. 1994. Positive interactions in communities. - Trends Ecol. Evol. 9: 191-193.

Bilton, D. T. et al. 2001. Dispersal in freshwater invertebrates. Annu. Rev. Ecol. Syst. 32: 159-181.

Cebrian, J. 1999. Patterns in the fate of production in plant communities. - Am. Nat. 154: 449-468.

Chase, J. M. and Leibold, M. A. 2003. Ecological niches. - Univ. of Chicago Press.

Chase, J. M. 2007. Drought mediates the importance of stochastic community assembly. - Proc. Natl Acad. Sci. USA 104: $17430-17434$.

Chisholm, C. et al. 2011. Metacommunity diversity depends on connectivity and patch arrangement in heterogeneous habitat networks. - Ecography 34: 415-424.

Connor, E. F. and Simberloff, D. 1979. The assembly of species communities: chance or competition? - Ecology 60: 1132-1140.

Diamond, J. M. 1975. Assembly of species communities. - In: Cody, M. L. and Diamond, J. M. (eds), Ecology and evolution of communities. Harvard Univ. Press, pp. 342-444.

Elwood, M. D. F. et al. 2009. Stochastic and deterministic processes jointly structure tropical arthropod communities. Ecol. Lett. 12: 277-284.

Fischer, J. and Lindenmayer, D. B. 2007. Landscape modification and habitat fragmentation: a synthesis. - Global Ecol. Biogeogr. 16: 265-280.

Fukami, T. et al. 2010. Assembly history dictates ecosystem functioning: evidence from wood decomposer communities. Ecol. Lett. 13: 675-684.

Gessner, M. O. et al. 2010. Diversity meets decomposition. Trends Ecol. Evol. 25: 372-380.

Gonzalez, A. and Chaneton, E. J. 2002. Heterotrophic species extinction, abundance and biomass dynamics in an experimentally fragmented microecosystem. - J. Anim. Ecol. 71: 594-602.

Gotelli, N. J. 2000. Null model analysis of species co-occurrence patterns. - Ecology 81: 2606-2621.

Gotelli, N. J. and McCabe, D. 2002. Species co-occurrence: a meta-analysis of J. M. Diamond's assembly rules model. Ecology 83: 2091-2096.
Gotelli, N. J. and Rohde, K. R. 2002. Co-occurrence of ectoparasites of marine fishes: a null model analysis. - Ecol. Lett. 5: 86-94.

Gotelli, N. J. and Entsminger, G. L. 2010. EcoSim: null models software for ecology. Ver. 7. - Acquired Intelligence Inc. and Kesey-Bear. Jericho, VT 05465.

Haddad, N. and Tewksbury, J. J. 2005. Low quality habitat corridors as movement conduits for butterflies. - Ecol. Appl. 15: 250-257.

Hairston, N. G. Jr and Hairston, N. G. Sr 1997. Does food web complexity eliminate trophic level dynamics? - Am. Nat. 149: 1001-1007.

Hanski, I. 1994. A practical model of metapopulation dynamic. - J. Anim. Ecol. 63: 151-162.

Hanski, I. 1999. Metapopulation ecology. - Oxford Univ. Press.

Hladyz, S. et al. 2009. Resource quality and stoichiometric constraints on stream ecosystem functioning. - Freshwater Biol. 54: 957-970.

Hubbel, S. P. 2001. The unified neutral theory of biodiversity and biogeography. - Princeton Univ. Press.

Jenkins, D. G. 2006. In search of quorum effects in metacommunity structure: species co-occurrence analyses. - Ecology 87: 1523-1531.

Jonsson, M. T. et al. 2008. Colonization and extinction patterns of wood-decaying fungi in a boreal old-growth Picea abies forest. - J. Ecol. 96: 1065-1075.

Krasnov, B. R. et al. 2006. Are ectoparasites communities structured? Species co-occurrence, temporal variation and null models. - J. Anim. Ecol. 75: 1330-1339.

Lawton, J. 1994. What species do in ecosystems? - Oikos 71: 367-374.

Leibold, M. A. et al. 2004. The metacommunity concept: a framework for multi-scale community ecology. - Ecol. Lett. 7: 601-613.

Michels, E. et al. 2001. Zooplankton on the move: first results on the quantification of dispersal of zooplankton in a set of interconnected ponds. - Hydrobiologia 442: 117-126.

Moilanen, A. and Hanski, I. 2001. On the use of connectivity measures in spatial ecology. - Oikos 95: 147-151.

Moore, J. C. et al. 2004. Detritus, trophic dynamics and biodiversity. - Ecol. Lett. 7: 584-600.

Paradise, C. J. and Dunson, W. A. 1997. Insect species interactions and resource effects in treeholes: are helodid beetles bottom-up facilitators of midge populations? - Oecologia 109: 303-312.

Patterson, B. D. and Atmar, W. 1986. Nested subsets and the structure of insular mammalian faunas and archipelagos. Biol. J. Linn. Soc. 28: 65-82.

Pielou, D. P. and Pielou, E. C. 1968. Association among species of infrequent occurrence: the insect and spider fauna of Polyporus betulinus (Bulliard) Fries. - J. Theor. Biol. 21: 202-216.

Reice, S. R. 1991. Effects of detritus loading and fish predation on leafpack breakdown and benthic macroinvertebrate in a woodland stream. - J. N. Am. Benthol. Soc. 10: 42-56.

Rosenfeld, J. 2000. Effects of fish predation in erosional and depositional habitats in a temperate stream. - Can. J. Fish. Aquat. Sci. 57: 1369-1379.

Sanders, N. J. et al. 2003. Community disassembly by an invasive species. - Proc. Natl Acad. Sci. USA 100: 2474-2477. 
Schoner, T. W. and Adler, G. H. 1991. Greater resolution of distributional complementarities by controlling for habitat affinities: a study with Bahamian lizards and birds. - Am. Nat. 137: 669-692.

Spencer, M. et al. 2002. Are there fine-scale spatial patterns in community similarity among temporary freshwater pools? Global Ecol. Biogeogr. 11: 71-78.

Staddon, P. et al. 2010. Connectivity, non-random extinction and ecosystem function in experimental metacommunities. - Ecol. Lett. 13: 543-552.

Stone, L. and Roberts, A. 1990. The checkerboard score and species distributions. - Oecologia 85: 74-79.

Strauss, S. Y. and Irwin, R. E. 2004. Ecological and evolutionary consequences of multispecies plant-animal interactions. Annu. Rev. Ecol. Evol. Syst. 35: 435-466.

Tello, J. S. et al. 2008. Patterns of species co-occurrence and density compensation: a test for interspecific competition in bat ectoparasite infracommunities. - Oikos 117: 693-702.
Tewksbury, J. J. et al. 2002. Corridors affect plants, animals, and their interactions in fragmented landscapes. - Proc. Natl Acad. Sci. USA 99: 12923-12926.

Tilman, D. 1982. Resource competition and community structure. - Princeton Univ. Press.

Tokeshi, M. 1999. Species coexistence: ecological and evolutionary perspectives. - Blackwell Science Ltd.

Ulrich, W. 2004. Species co-occurrence and neutral models: reassessing. - Oikos 107: 603-609.

Valentini, A. et al. 2009. DNA barcoding for ecologists. - Trends Ecol. Evol. 24: 110-117.

Van de Meutter, F. et al. 2006. Lotic dispersal of lentic invertebrates. - Ecography 29: 223-230.

Weiher, E. and Keddy, P. 1999. Ecological assembly rules, advances, retreats: perspective. - Cambridge Univ. Press.

\section{Appendix 1}

Table A1. List of sampled macroinvertebrates on Phragmites australis leaf detritus and incidence on the five sampling stations.

\begin{tabular}{llccccc}
\hline Genus & Species & Pool 1 & Pool 2 & Pool 3 & Pool 4 & Pool 5 \\
\hline Gammarus & aequicauda & $\mathrm{x}$ & $\mathrm{x}$ & $\mathrm{x}$ & $\mathrm{x}$ & $\mathrm{x}$ \\
Nereis & diversicolor & $\mathrm{x}$ & $\mathrm{x}$ & $\mathrm{x}$ & $\mathrm{x}$ & 0 \\
Chironomus & spp. & $\mathrm{x}$ & $\mathrm{x}$ & 0 & 0 & 0 \\
Hydrobia & acuta & $\mathrm{x}$ & $\mathrm{x}$ & 0 & 0 & 0 \\
Perinereis & cultrifera & 0 & $\mathrm{x}$ & 0 & 0 & 0 \\
Cerithium & rupestre & 0 & 0 & $\mathrm{x}$ & $\mathrm{x}$ & $\mathrm{x}$ \\
Haliplus (larvae) & & $\mathrm{x}$ & $\mathrm{x}$ & 0 & 0 & 0 \\
Spio & decoratus(?) & $\mathrm{x}$ & 0 & 0 & 0 & 0 \\
Cerastoderma & glaucum & $\mathrm{x}$ & $\mathrm{x}$ & $\mathrm{x}$ & $\mathrm{x}$ & 0 \\
Acilius & & $\mathrm{x}$ & $\mathrm{x}$ & 0 & 0 & 0 \\
Gordius & & 0 & $\mathrm{x}$ & 0 & 0 & 0 \\
Haliplus & & $\mathrm{x}$ & 0 & 0 & 0 & 0 \\
Hydrophilus & baltica & 0 & 0 & 0 & 0 & 0 \\
Idotea & insidiosum & 0 & $\mathrm{x}$ & 0 & 0 & $\mathrm{x}$ \\
Corophium & & & & 0 & 0 \\
\hline
\end{tabular}




\section{Appendix 2}

Table A2. Main chemical-physical parameters measured during the field experiment. Values are given as mean $( \pm$ SD).

\begin{tabular}{lccc}
\hline Pool & $\begin{array}{c}\text { Salinity } \\
\mathrm{mg} \mathrm{l}^{-1}\end{array}$ & $\begin{array}{c}{\left[\mathrm{O}_{2}\right]} \\
\mathrm{mg} \mathrm{l}^{-1}\end{array}$ & $\mathrm{pH}$ \\
\hline 1 & $44.769( \pm 4.746)$ & $5.765( \pm 2.543)$ & $8.112( \pm 0.243)$ \\
2 & $50.531( \pm 5.126)$ & $6.068( \pm 2.703)$ & $8.104( \pm 0.252)$ \\
3 & $87( \pm 10.083)$ & $5.505( \pm 1.568)$ & $8.067( \pm 0.296)$ \\
4 & $100.154( \pm 12.548)$ & $5.865( \pm 1.216)$ & $8.134( \pm 0.236)$ \\
5 & $115( \pm 29.958)$ & $5.536( \pm 1.779)$ & $8.034( \pm 0.187)$ \\
\hline
\end{tabular}

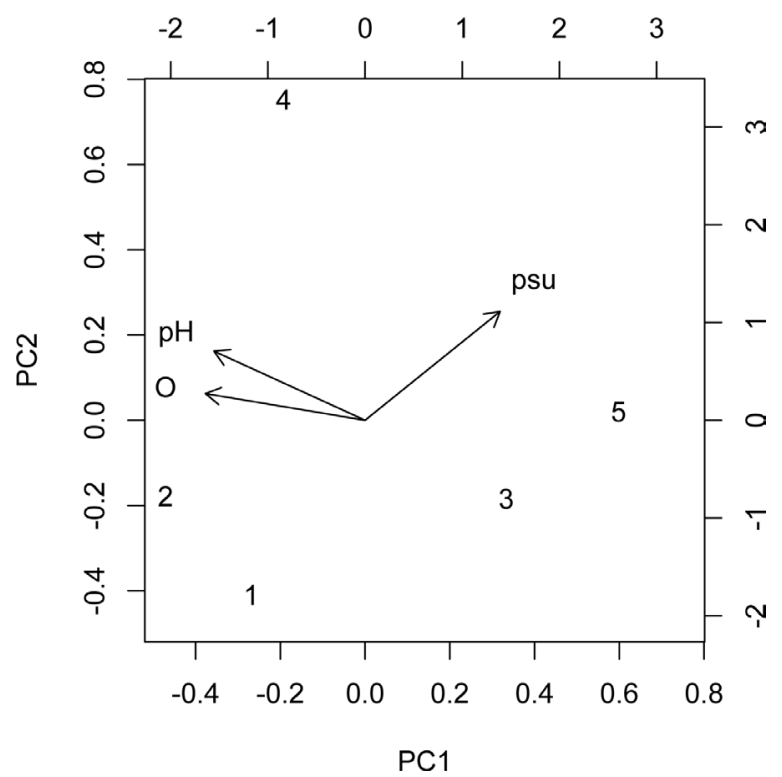

Figure A1. PCA ordination. 